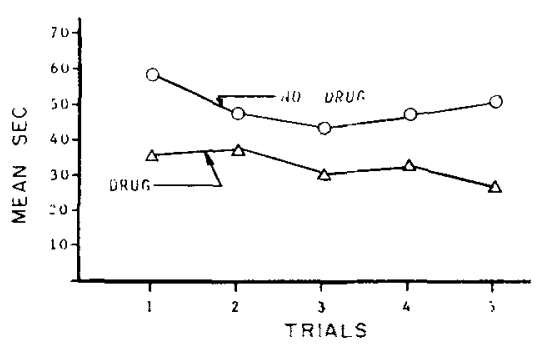

Fig. 2. Time for 15 presses in the goalbox of the $\mathrm{C}$-maze at the end of each of the five trials when Ss were and were not given sodium amytal. The data points are means of Days 1-5 and 6.8 of Fig. 1 .

Deutsch's description of intracranial reinforcement. When drugged, this second $S$ ran all trials faster; the mean running time for first trial without drug was $17 \mathrm{sec}$, with drug it was $9 \mathrm{sec}$, and there was no overlap in distributions. For the second $S$, rate of pressing, on the average, was less with the drug but not uniformly less. The third hippocampal $S$ did not change on running times or on pressing rate from days of placebo to days of drug; it ran all first trials in about 12 sec. Running times of two amygdaloid Ss, particularly first-trial running times, were reduced with the drug: Mean first trial for one changed from $118 \mathrm{sec}$ to $74 \mathrm{sec}$ (with one drug score within the range of placebo scores) and for the other from $128 \mathrm{sec}$ to $13 \mathrm{sec}$ (with no overlap in distributions). The running times of the third amygdaloid $\mathbf{S}$ did not change with drug administration. Whether drugged or not, the third $S$ ran all trials in about $20 \mathrm{sec}$. The time for all three amygdaloid Ss to take the allotted presses at the end of a trial was reduced, the most dramatic reduction being with the $S$ without change in running times: Mean time for 25 presses for first trial on days of placebo was $314 \mathrm{sec}$, and for days of drug, it was $28 \mathrm{sec}$, with no overlap in distributions.

The marked facilitation caused by the drug for the hippocampal $S$ that initially pressed and ran very slowly suggested that giving sodium amytal might change some Ss that had never pressed for ICS into pressers. In an informal study, a number of hippocampal Ss that had never pressed for ICS at above-operant rates, despite plenty of opportunity, were retested under the influence of the dnug. Even with extensive attempts to shape pressing, none of them ever showed sustained pressing. The facilitative effect is limited, apparently, to Ss that show some positive reinforcement without the drug.

Sodium amytal dramatically decreases running times for ICS in those Ss that exhibit a marked discrete-trial performance decrement. Moreover, the reduction in running time occurs on the first trial following injection of the drug, indicating that it is not because of a drug-induced qualitative change in the electrical stimulation, since the $S$ has yet to experience the ICS under the drugged state. The conclusion is that a noxious event frequently accompanies predominantly positive ICS, and that this noxious event is responsible for the discrete-trial performance decrement.

\section{REFERENCES}

DEUTSCH, J. A., \& DEUTSCH, D. Physiological psychology. Homewood, Ill: Dorsey, 1966.
MILLER, N. E. Some recent studies of confict behavior and drugs. American Psychologist, $1961,18,12-24$.

WASDEN, R. E., \& REID, L. D. Intracranial stimulation: Performance decrements and a fear-reducing drug. Psychonomic Science, $1968,12,117-118$.

WASDEN, R. E., REID, L. D. \& PORTER, P. B. Overnight decrement with intracranial reinforcement. Psychological Reports, 1965, $16,653-658$.

NOTES

1. Supported in part by funds of the Faculty Research Committee, Bradley University.

2. The following undergraduate colleagues actively participated in the gathering of these data: Steven R. Rapp, Larry D. Sensenig, Richard F. Wellbrock, and Thomas W. Westcott

\title{
The effect of partial "quinine" reward on acquisition and extinction ${ }^{1}$
}

PAUL T. P. WONG, ${ }^{2}$ JOHN SCULL, and ABRAM AMSEL, ${ }^{2}$ University of Toronto, Toronto, Canada

During acquisition of a hunger-motivated running response, on $50 \%$ of the trials, food reward was adulterated with quinine sulphate. This treatment resulted in inferior acquisition performance, but had no effect on resistance to extinction compared to a continuous reinforcement control.

According to a more general theory of persistence proposed by Amsel (1968), whenever an organism maintains its ongoing behavior $\left(R_{0}\right)$ in the face of any disruptive or aversive event $\left(S_{X}\right)$, some degree of $S_{X} \rightarrow R_{0}$ counterconditioning is involved, and this counterconditioning should lead to some increment in persistence in the face of subsequent disruptive events. Some empirical support for this notion has already been reported (Brown \& Wagner, 1964; Fallon, 1968; Logan, 1960). Recently, in our laboratory, both negative (Wong, 1968) and positive results (Amsel, Wong, \& Scull ${ }^{3}$ ) have been obtained. The aim of the present study was to see if approach training in the face of quinine aversion would lead to greater resistance to extinction as predicted by the theory.

\section{METHOD}

Twenty male albino rats, about 70 days old upon arrival in the laboratory, were housed in individual cages and maintained on a $10-\mathrm{g} / 23-\mathrm{h}$ food-deprivation schedule and ad lib water throughout the 10 days of handling and 26 days of experimental training.

A straight wooden runway contained an 11-in. startbox, a 26-in. alley, and a 13-in. goalbox, all separated by guillotine-type doors. All segments were 3 in. high and $2.7 / 8$ in. wide, covered with a clear Plexiglas lid. The alley and goal segments were painted flat black, while the startdoor was grey. Three $1 . \mathrm{ft}$ time measures were taken by a microswitch on the startdoor and three photocells on the runway. Two identical aluminum foodcups, $2 \times 1 \times 1$ in., were used, one for the "good" Noyes pellet and one for the quinine pellet. The foodcup was attached to the end plate, about $1 / 4 \mathrm{in}$. above the floor.

The Ss were assigned randomly to either the partial quinine (PQ) group or the CRF control. All Ss had 21 days of acquisition and 5 days of extinction, two trials per day on the first 2 days of acquisition but four trials per day for the remainder of the experiment. Minimum ITI was about 20 min. Reward magnitude on each trial was one 250 -mg Noyes pellet.

Noyes pellets were soaked in a mixture of $1 / 2$ water and $1 / 2$ albumen for $1.4 \mathrm{~min}$ for a "good" reward trial (R). For quinine reward, the pellet was soaked in an identical mixture except that it contained quinine sulphate. On Days 1-5, quinine concentration was approximately $.12 \mathrm{~g} / \mathrm{ml}$, and on the remaining days, it was $.16 \mathrm{~g} / \mathrm{ml}$. 


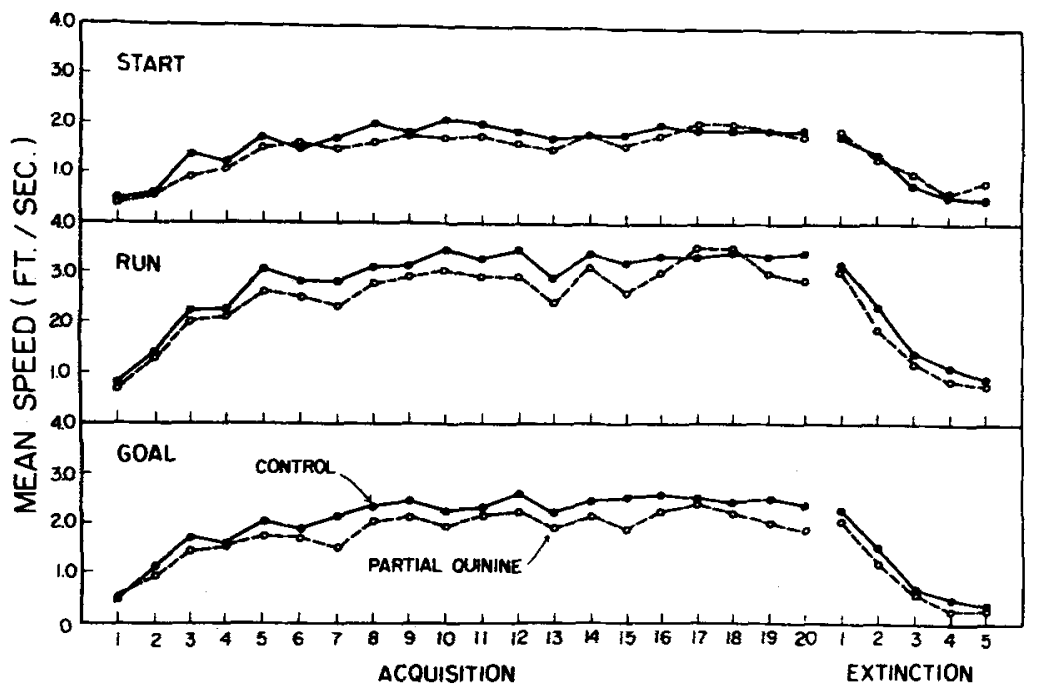

DAYS (BLOCKS OF 4 TRIALS)

For the $P Q$ group, $Q$ trials occurred on a $50 \%$ basis. The distribution of $Q$ trials was according to a recursive four-block sequence: RRQQ, RQQR, QRRQ, QQRR. In this sequence, frequencies of within-block $R R, R Q, Q Q, Q R$ transitions were equal.

On each trial, $S$ was placed in the startbox, and the startdoor was raised as soon as $\mathrm{S}$ was oriented to it. The goalbox door was lowered only when the last photobeam had been interrupted. During acquisition, $S$ was removed from the goalbox after completion of eating (about $30 \mathrm{sec}$ on $R$ trials, but about $60 \mathrm{sec}$ on $Q$ trials). During extinction, goalbox confinement was about $30 \mathrm{sec}$. After each trial, the goalbox floor was wiped with a damp cloth. On any trial, if $\mathbf{S}$ failed to break the last photobeam in $3 \mathrm{~min}$, it was placed in the goalbox. Any time measure greater than $60 \mathrm{sec}$ was recorded as $60 \mathrm{sec}$.

On each day, rats were carried into the experimental room in two 12-unit carrying cages. All Ss were given their daily ration of food about $30 \mathrm{~min}$ after being returned to their home cages.

\section{RESULTS AND DISCUSSION}

Time scores were transformed into speeds ( $1 /$ time), and mean speeds are shown in Fig. 1. During acquisition, the $P Q$ group appeared inferior in all three measures. There was a cross-over in the start and run measures. However, none of the treatment main effects nor the Treatment by Day interaction reached the .05 level of significance. Only the day effect was statistically significant in all measures $[F(19,342)=33.06,63.73$, $33.74, \mathrm{p}<.01$ in all cases]. During extinction, again only significant day

Fig. 2. Retrace data from acquisition and extinction. $86.82,94.41, \mathrm{p}<.01]$. $\mathrm{p}<.05$, one-tail] left unfinished.
Fig. 1. Speed data from acquisition and extinction.

end of acquisition suggests that some counterconditioning had taken place. However, there was no evidence of increased persistence for the $\mathrm{PQ}$ group as expected. This negative result could be due to insufficient counterconditioning. It remains an empirical question whether or not the predicted result could be obtained with gradually increased quinine concentration and prolonged acquisition training.

In view of the fact that the bitter taste of quinine persists for more than an hour, a one-trial-per-day procedure is recommended for further research using quinine reward.

\section{REFERENCES}

effects were obtained $[F(4,72)=49.18$,

Retrace data appear in Fig. 2. On any given trial, only the first retrace was recorded. Mean numbers of retraces during acquisition were significant $[\mathrm{t}(18)=2.10$,

Both speed and retrace data suggest that quinine treatment did have the intended aversive effect on approach response. Such typical approach-avoidance conflict behavior as halting and retracing, especially near the goal, was frequently observed in $\mathrm{PQ}$ Ss. On some $\mathrm{Q}$ trials, consummatory response was interrupted by mouth-washing behavior and other competing responses while the quinine pellet was dropped on the floor. Although sometimes it took more than $5 \mathrm{~min}$ to finish eating the "bad" pellet, it was never

The fact that there was a cross-over and complete vanishing of retraces towards the

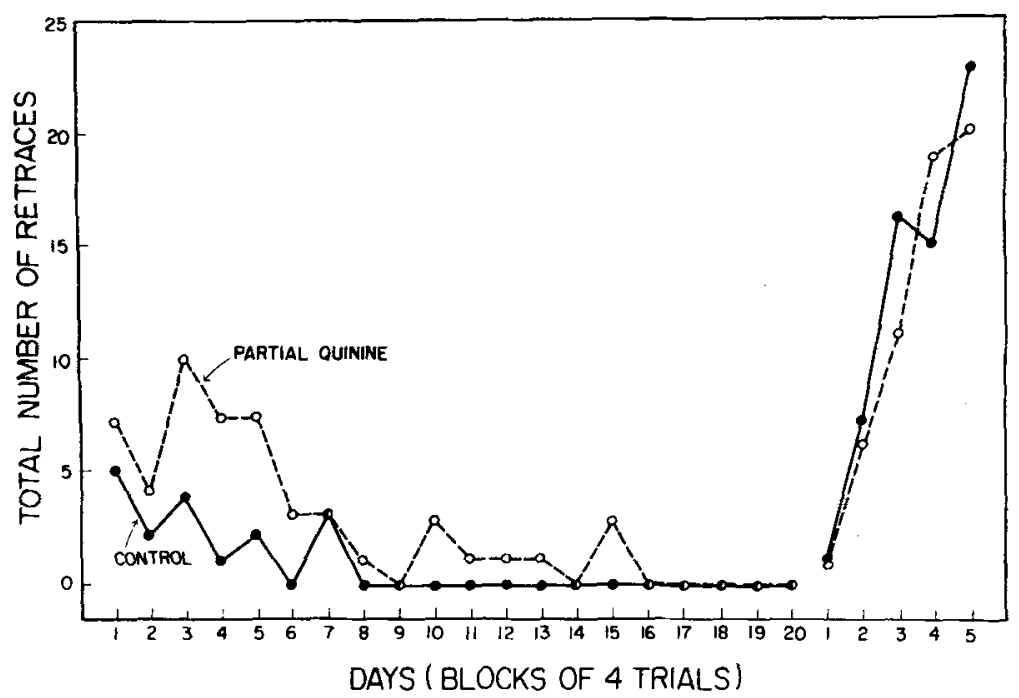

